\title{
Interaction between stewardship and social health insurances: A comparative and document analysis
}

\author{
Aslan Nazari ${ }^{1}$, Iravan Masoudi Asl ${ }^{2 *}$, Masoud Abolhallaje ${ }^{3}$, Amir Ashkan Nasiripour ${ }^{4}$, \\ Mohammad Javad Kabir ${ }^{5}$
}

Received: 10 Apr $2018 \quad$ Published: 26 Aug 2018

\begin{abstract}
Background: Social health insurances provide protection to access affordable coverage of services and stewardships of health system need to intervene to fulfill these objectives. This study conducted to assess interaction between stewardship and social health insurances.

Methods: This qualitative study conducted in two phases as comparative study and document analysis in 2018. Comparative study employed to identify the dimensions and requirements of interaction between stewardship of health systems and social health insurances in countries around the world. In document analysis, all evidence about Iran health financing reviewed. Data extraction forms were used to gather data.

Results: There were less interaction between stewardship and social health insurances in revenue collection and risk pooling. Advisory role of stewardship and proposals to coverage of uninsured people and performing risk analysis were some examples of such interaction. In Iran's health system, where stewardship plays a magnificent role in service provision, the basis of interactions are contracts, payment systems and timeline of payments.

Conclusion: Mechanisms of interaction in Iran is not clear or does not work properly. Thus, nonstructural merging of social health insurances needs to redefine these mechanisms.
\end{abstract}

Keywords: Stewardship, Health system, Social health insurances, Interaction, Iran

Copyright@ Iran University of Medical Sciences

Cite this article as: Nazari A, Masoudi Asl I, Abolhallaje M, Nasiripour AA, Kabir MJ. Interaction between stewardship and social health insurances: A comparative and document analysis. Med J Islam Repub Iran. 2018 (26 Aug);32:77. https://doi.org/10.14196/mjiri.32.77

\section{Introduction}

Many households, estimated more than 100 million people, face catastrophic health expenditure each year (1). In this regard, of the main methods of financing patients are health insurance and universal coverage (2).

Recently, low and middle income countries have been interested in developing social health insurance to cover the entire population of the country (2). Therefore, stewardship of health systems should help to achieve universal coverage and financial protection. Health systems through stewardship and their interaction with provision and health financing, play a critical role in improving health and also are responsible for financial protection in general and specialty hospitals (3-5). Stewardship in health systems can

Corresponding author: Dr Iravan Masoudi Asl, masoudi_1352@yahoo.com

1. Department of Health Services Management, Science and Research Branch, Islamic Azad University, Tehran, Iran.

2. Department of Health Services Management, School of Health Management and Information Sciences, Iran university of medical sciences, Tehran, Iran.

3. Budgeting and Performance Monitoring Center, Ministry of Health and Medical Education, Tehran, Iran.

4. Department of Health Services Management, Science and Research Branch, Islamic Azad University, Tehran, Iran.

5. Health Management \& Social Development Research Center, Gorgan University of Medical Sciences, Gorgan, Iran. recognize uninsured people, warranty better purchasing and develop community insurances (6-8).

To this regard, several methods have been implemented in different countries to carry out effective interventions. Recent reforms in Turkey through the implementation of universal coverage and the health equity (9), in Latin American countries to increase the covered population (10), improving the quality of services provided in Romania by implementation of quality systems and coordinating between different levels of services (11), financing reforms in Chile and difficulties in ensuring access to affordable services (12) are part of recent interventions in health systems in different countries. In particular, recog-

$\uparrow$ What is "already known" in this topic:

Scientific research in interactions of stewardship and health financing does not exist and mechanisms of these interactions are not clear. There are financial challenges between Ministries of Health and social health insurances after health transformation plan (HTP) in 2014

$\rightarrow$ What this article adds:

In Iran, there were poor interaction between stewardship and social health insurances in revenue collection and risk pooling. 
nizing uninsured people and cover them through in Pakistan (7) and community insurances in Japan (8) which has received a large proportion of insurance funds are among the special experiences in health financing. Interventions in different countries may be carried out for an individual or a set of functions. However, the issue of interaction between components, and not just the effective functioning of one component, leads to sustained effectiveness of an intervention. Therefore, it is necessary to intervene in the health system financing of Iran.

Interaction is a reciprocal relationship between two or more actors/agents in which the exchange process is given in terms of a shared pattern and conceptual mediation (13). Despite its importance, patterns of interaction are questionable in provision of quality health services in a continuous manner in financing and social and health insurance, coordination in the health system, and stewardship challenges $(14,15)$. Interaction between the components of stewardship and social health insurances is critical because the proper function of one component is heavily influenced by the impact and proportional performance of other components. As an example, Mexico, by focusing on the role Mexican Ministry of Health, has maintained an effective interaction between the components of health policy-making and stewardship of health services and has also enabled effective areas for protecting patients' finances and the community members' coverage $(16,17)$.

The multiplicity of health insurance funds has made insurance companies in each country have their own approach. To this regard, some of raised challenges to the process of interaction between stewardship and social health insurances include the unmatched scope and nature of various insurance funds activities; different organizations and structures in insurance companies; the accumulation of different risks between funds due to different sizes and different age groups with different risks covered by each fund; unmatched resources of income and savings accounts for various insurance organizations; different service packages; different service packages and service purchases for the population covered by each insurance fund and the way of paying demands to providers.

To address the challenges to the health financing system of Iran requires the acquisition of financing components for effective interventions. This can be done through col- laboration, coordination and interaction among components. Therefore, studying the health status of Iran shows that the biggest problems are lack of interaction between the health system and insurance in the field of financing. In this regard, the present study conducted to assess mechanisms of interaction between stewardship of health systems and social health insurances or funds.

\section{Methods}

This qualitative study was carried out in two stages of comparative and document analysis in 2017. In comparative research paradigms are identified and the status, experiences and characteristics of the subject are investigated (18). To this end, initially, various dimensions of interaction between the Ministry of Health, as a health system and social health insurance as a health sector were identified. Then, online sites and centers related to the health system financing in various countries were searched and some countries were selected for analysis based on inclusion criteria including having hospital sector health system with the public sector prevalence, a clear financing system, leading in the health system reform, having financial health experience in the health system, and having at least one published article in the field.

Data extraction form was used to collect data from selected countries. First, based on the literature review, the minimum variables of the interaction between the Ministry of Health and Social health insurances were identified and the data extraction form was designed. The information at this stage was collected through referring to books, journals, and authoritative sites including the World Bank website, World Health Organization, as well as Google scholar, ProQuest, Emerald, PubMed, Springer, Index Copernicus, Web of Science, Science Direct, and Scopus.

All studies in the field of insurance and health were investigated with following keywords; Financing, Health System, Revenue Collection, Risk Pooling, Purchasing, Interaction, Health Insurance. Documents included in this study which contain types of interactions (342 documents). All abstract and full texts were reviewed by two researchers. Mechanisms of interaction were found in 11 documents and these documents summarized by research team (Fig. 1). In order to analyze and compare the data,
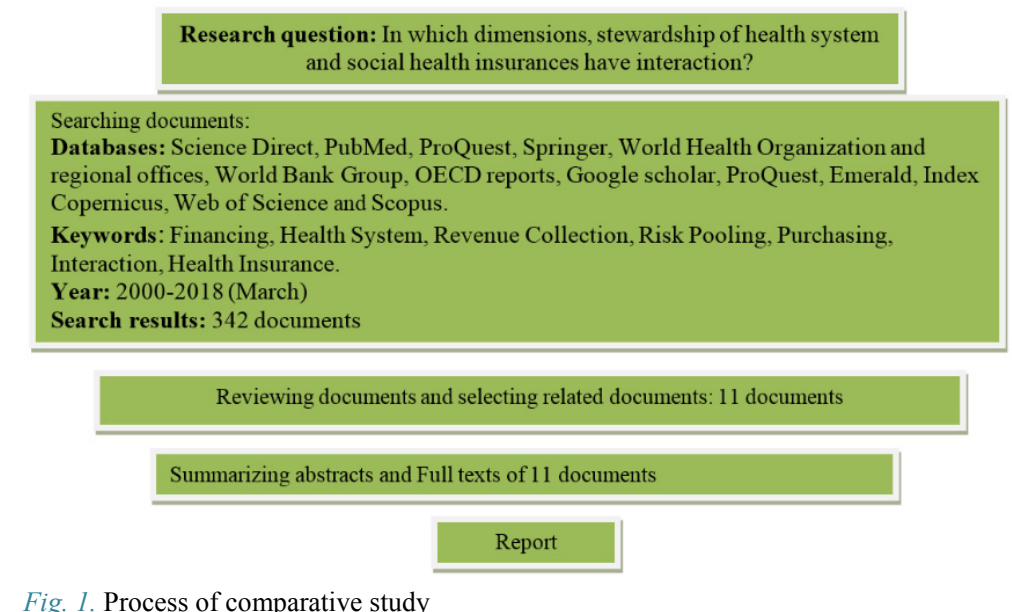
comparative tables were used at this stage which included identification of interactive approaches of the Ministry of Health and social health insurances obtained from financing investigation in the studied countries. Therefore, the data were entered into a comparative table as the basis for the analysis and comparison of countries. To analyze similarities and differences of these dimensions, including collecting resources, accumulation and purchasing of services were analyzed.

In the document analysis phase, all studies, documents, reports, and existing models were related to the health system macro structure framework in Iran. Related global models were the World Health Organization 2000 model and related upstream documents, such as the 1404 Vision Document, General Health Policies, Territorial Policies, Legislation, Supreme Council Conclusions, and reports of related organizations such as the Expediency Council and the Research Center of the Islamic Consultative Assembly and the Academy of Medical Sciences. A researcher-made checklist was used to collect related political documents. This checklist contained important items such as the title, type, general description of the document/report, the time and place of publication, the organization concerned, related issues with the content of the document/ report and related items to the content of the document.

\section{Results}

\section{Results of comparative phase:}

1. Revenue Collection: Collection of resources and the ways countries provided insurance funds were different (19). Some countries, such as Vietnam, have introduced a number of multiple competitive insurance systems and in some others, such as the United States, Germany, Netherlands, Belgium, and Switzerland, followed competitive health insurance market (20). In Netherlands, insurance companies can offer lower premiums (up to $10 \%$ ) to people who are registered through cumulative agreements. The premium rate can vary according to the type of coverage model (non-cash benefits against repayment) (21). In Germany, health insurance funds currently collect premiums as a same percentage of wages or gross income and premiums are collected in a national central fund, along with tax subsidies paid by the government to cover children (21). Some countries try to attract foreign donations, which is a model for interaction and cooperation between recipient governments and all stakeholders directly involved in the health sector. This approach aims to integrate all domestic and foreign funds with the state budget $(22,23)$ (Table 1).

2. Risk Pooling: In some countries, such as Mexico, they have dedicated certain resources for those who main-

Table 1. Interaction mechanisms in revenue collection in different countries

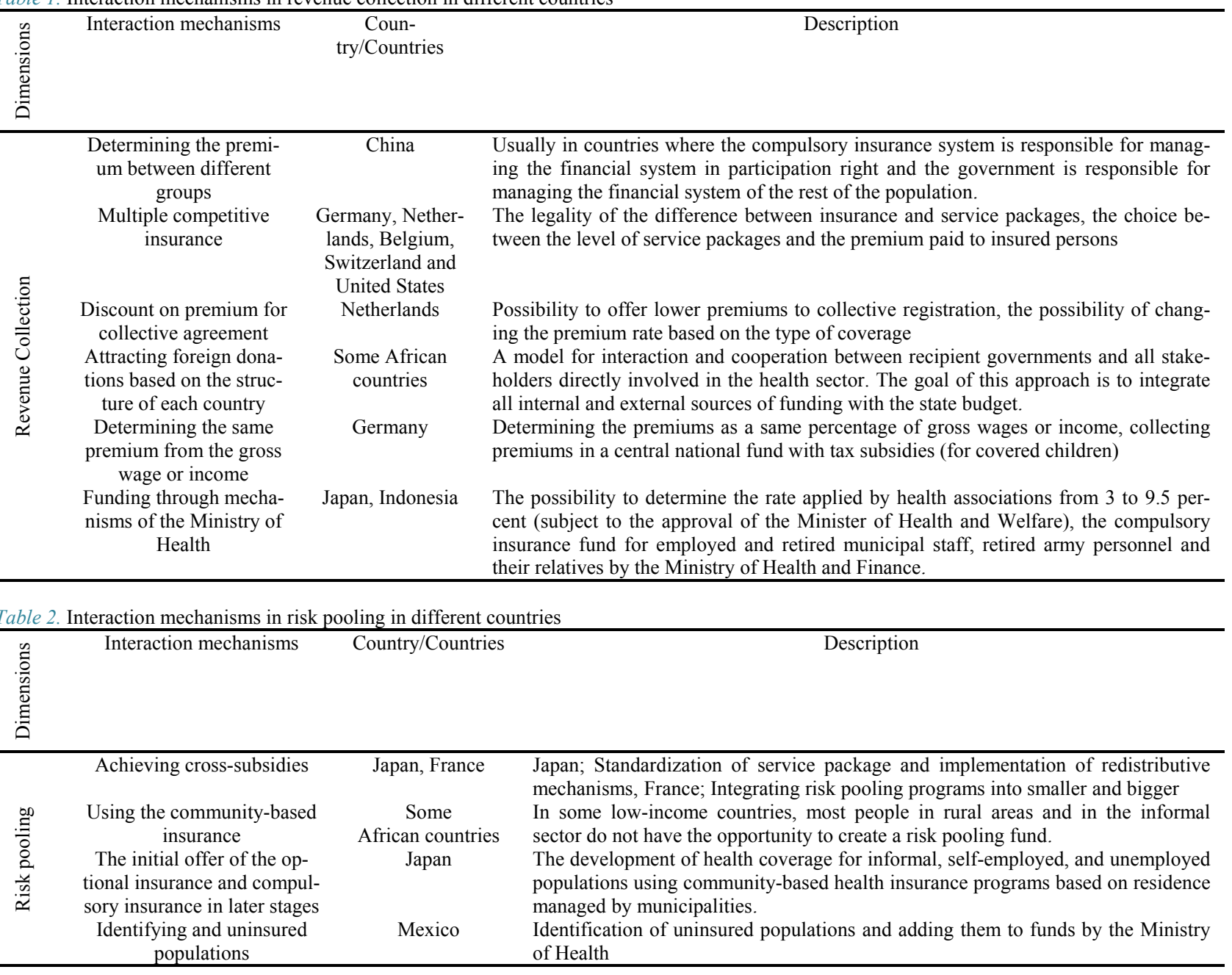


ly provide services for low-income groups. Therefore, the Ministry of Health, in addition to other tasks assigned, identifies uninsured populations and adds them to funds (24). In others, despite having multiple risk pooling funds, they have been able to achieve cross-subsidies by standardizing key aspects of the system and integrating risk pooling. Japan by standardizing of the service package and implementation of redistributive mechanisms and France by integrating less and bigger risk pooling programs have managed to achieve this goal in spite of the multiplicity of funds. In some low-income countries, where most people work in rural areas and there is no possibility of creating a risk pooling fund, the establishment of community-based schemes has become popular. Such plans began with African countries, often with fewer than a hundred members (25). Japan has developed health coverage to informal, self-employed, and unemployed populations by using health insurance plans based on residence managed by municipalities (26) (Table 2).

3. Purchasing services: In single-insurance systems, the insurer generally has a stronger position than insurance providers due to the exclusive purchasing power. Primary health services in countries of Austria, Belgium, France, Germany, Greece, Hungary, Japan, South Korea, Luxembourg and Poland, which have social health insurance, are compulsory for all or most of the population which the financing is through income-related social contributions and government revenue from public taxes. In these countries, insurance coverage is often related to people's occupation and is usually extended to the employed person's relatives. This is done in Belgium, Korea, Luxembourg, Poland and Turkey as a single payer and only one fund purchases basic health care services; however, in Austria, France, Greece, Japan and Mexico, service purchasing is not exclusively done by one fund (21) (Table 1). Countries such as Thailand and Chile have separated insurance and financial management from health services and established the National Health Fund to integrate all government health resources in a unit fund, to reduce overlap and provide a basis for implementing strategic purchases in the public sector (27).

Determining the method of payment to doctors in different countries can also be done by interacting between health insurance providers. In Belgium, the method of payment to doctors is determined by cumulative social health insurance, individual health insurance and providers. In France, this is done by federal or central government and social health insurance, and in Slovakia, it is exclusively related to the health insurance (21). Determining payment method for a hospital is also diverse in dif-

Table 3. Interaction mechanisms in purchasing in different countries

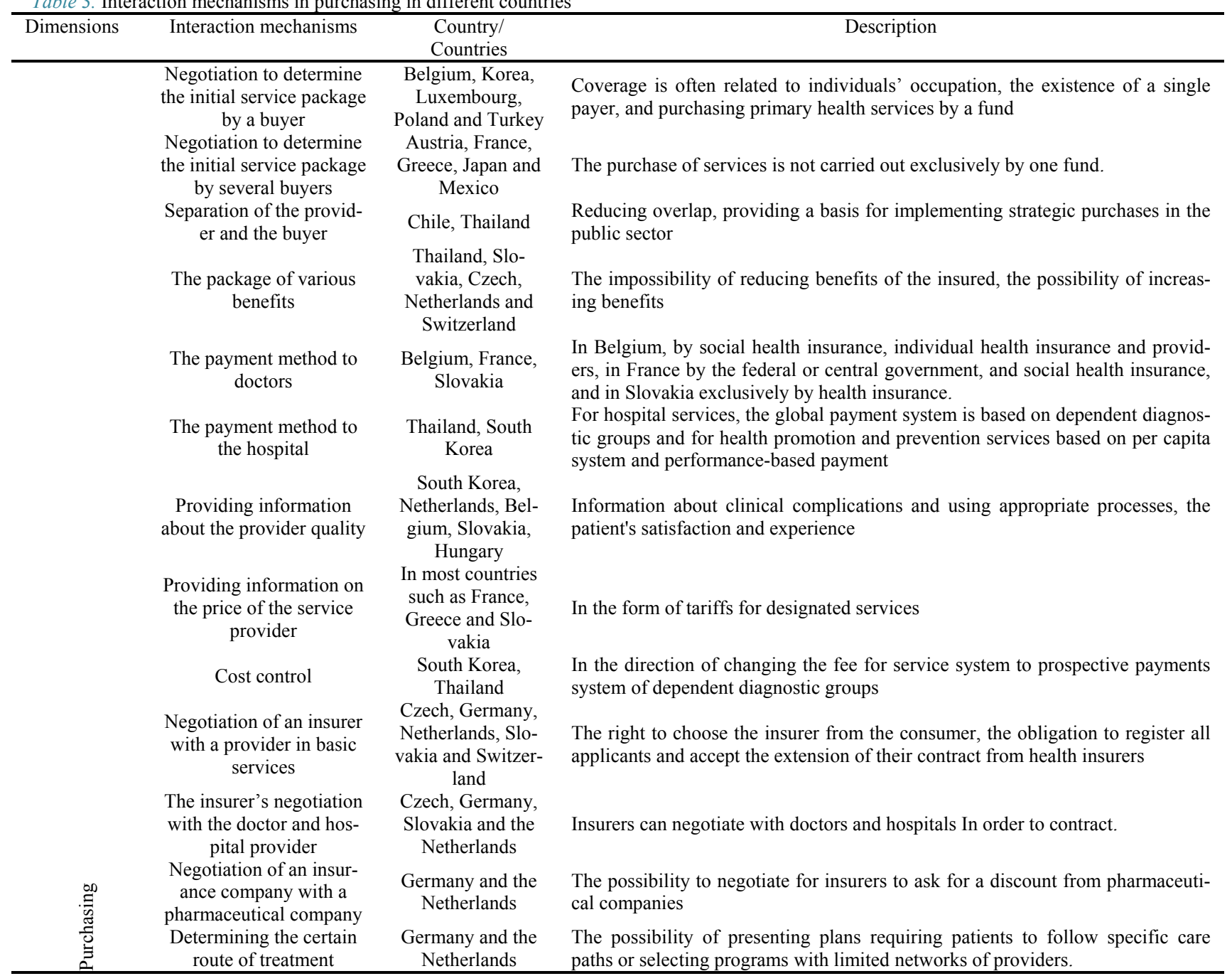


ferent countries; for example, in South Korea, the central or federal government, social health insurance, and cumulative providers determine the type of payment to the hospital (21). For hospital services the global payment system depended on diagnostic groups is used. Furthermore, preventive and health promotion services are part of the basic package and the payment method to their providers are based on the per capita system and performance-based payment (28). In Slovakia, Czech Republic and Netherlands, there is no possibility to reduce benefits of the insured, and there is only a possibility to increase benefits. However, in Switzerland, in return for fewer premiums, the insured can use managed care services (21) (Table 3).

Regarding the quality level of services offered by providers, in South Korea, insurers provide information on clinical implications and use appropriate processes. In Netherlands, insurers and the media report clinical outcomes, using appropriate processes, patients' satisfaction and experiences; furthermore, information about the price of provided services is also available in different countries, and insurers have options to purchase services. An example of price information for services or tariffs in France, Greece and Slovakia is available. In purchase of basic health services, considering the consumer's right to choose the insurer is a prerequisite for a real competition in the health insurance market. Five countries of Czech Republic, Germany, Netherlands, Slovakia and Switzerland offer consumers the right to choose the insurer. In all these countries, health insurers are required to enroll all applicants and accept their contract extension (21). In order to change the fee for service system to prospective payments system, the dependent diagnostic groups of this system were implemented voluntarily in South Korea and Thailand in several centers (29). In four countries of Czech, Germany, Slovakia and Netherlands, insurers can negotiate with doctors and different hospitals in order to contract. In Germany and Netherlands, insurers are also in a position to ask for a discount from pharmaceutical companies, and in these countries, insurers also have the possibility to present plans that require patients to follow special care paths or to select plans with limited networks of providers (21) (Table 3).

\section{Results of Document Analysis phase}

The General Health Policies (GHPs) of the Islamic Republic of Iran imparted by the Supreme Leader of Iran were examined. In $7^{\text {th }}$ item of these policies, the stewardship functions separation, financing, and provision of services in the field of health are described with the aim of responding, realizing justice, and providing good therapeutic services to people. In item $2-7$, the management of health resources is provided through the insurance system of Iran Ministry of Health and Medical Education and the cooperation of other centers and institutions. By elaborating the policy and analyzing other health policies and upstream legislation such as the constitution, vision and similar regulations (other communicative policies and theoretical theories), the issue of $8^{\text {th }}$ policy can be explained, described and stipulated to have definite functional and planed effects.
The acceptance of the insurance system as the main method of financing has several consequences; (A) the health system will operate out of the national medicine method and will act as a health insurance (buyer and seller), B) according to the principle of separation, the buyer and the seller must have a certain legal role and personality and therefore the contractual relations must be formulated, developed and enforced, C) the insurance must be a cognizant buyer and act with the role of providing resources and risk pooling, D) the basic insurance must provide all purchasing operations for health services with preventive priority to treatment ( $2^{\text {nd }}$ policy), E) the basic social insurance should play the role of intervention and controlling the health market; therefore, it should become as a unit purchaser in the health system to be effective in this market. Furthermore, the purchaser must provide basic health care services (Integrated Health Services Policy, F) with effective universal coverage at a reasonable depth ( $9^{\text {th }}$ Policy) to reduce people's share from costs, G) elimination of unnecessary services and expenditures ( $9^{\text {th }}$ Policy) and the same tariff for the public and nongovernmental sectors should also be highlighted in the insurance policies, and $\mathrm{H}$ ) Services defined outside the base package are covered by supplementary insurance (and not surplus insurance). Therefore, the necessity of interaction between the Ministry of Health and social health insurances is essential and the seriousness of the involved sets in this field is emphasized. Reviewing approvals of the Supreme Council of Insurance shows the interactive procedure of the Ministry of Health with social insurance funds. The review of approvals was carried out from 2004 to 2015. Among the interactions between the Ministry of Health and Social health insurances the following can be noted; Determining a percentage of people's salaries and income for health, Suggesting to cover certain groups such as members of the medical system, the bar association and non-insurance students, Determining the specific patients' responsibilities in the area of revenue collection, Determining tariffs for diagnostic and therapeutic services in the public and private sectors annually, Reviewing and correcting the provisions of the contract between the fund and providers, Implementation of family doctor program and referral system in selected provinces through coordination of provision and delivery, Suggesting to cover dental services, accelerating the provision of basic services, Healthy tourism and Foreigners' insurance, Establishing regulatory mechanisms for pharmacies' tariff, and the performance integrity of the base insurance funds in the area of service purchases.

\section{Discussion}

Functions and components of the health system and interactions between them considering the responsibility and duties of each function shape health outcomes (16, 30-32). Therefore, the present study was conducted with the aim of investigating the interactive relationship between the Ministry of Health as a health system and social welfare funds in the field of health financing.

Based on the findings of this study, the achievement of non-structural reforms in the field of health financing 
through coordinated approaches and the creation of interactions among influential collections is possible. These approaches are derived from three areas of revenue collection, risk pooling and purchasing of services in a comparative way. The proposal to cover groups of people who do not have basic health insurance, as a topic both in the studied countries and in the Supreme Council of Insurance, can indicate interactions between the stewardship and social insurance funds. This issue was also investigated in the study by Shi et al. in 2003 in China and some suggestions are presented for strengthening the social role of public hospitals in the form of financing basic service packages for poor and vulnerable people and increasing government subsidies at the level of primary hospitals for ease of access (32). However, it should be noted that, despite the great benefits, a lot of time are required to gain them. As Tinsley et al., in a 2014 study entitled "Are Massachusetts Healthcare Reforms Effective for Poor Workers? The Findings from Opportunity Analysis," showed that the net amount of coverage for poor workers in general and among investigated groups has increased. Furthermore, there was an increase in the coverage of poor workers during the years of reform; however, this has been lower in poor unemployed groups and rich people. The final conclusion of this study is that the increase in coverage in the form of financial protection reforms for patients and through the development of Medicaid, despite the increased coverage, has not effectively reduced the level of inequality in insurance coverage in Massachusetts (33).

Other findings of the study showed that although there is no complete information transparency on the way the Ministry of Health interacts in the area of financing as a health care system and social insurance funds, and how it is used, there are some experiences in general topics. Areas of review and policy on per capita treatment and diagnostic and therapeutic tariffs are among these interactions which are carried out continuously and annually. Using temporary or fixed committees is a feature that can be effective in completing expert actions among stakeholders. The concept of professional ethics in selected countries and in all sectors has been studied and examined.

The health in all policies in the form of general policies of health was announced by the Supreme Leader of the Islamic Republic of Iran in order to achieve perspective goals of Iran (1404), in 14 items and approaches of development plans and the health system development map in the form of governance policy was presented. The $7^{\text {th }}$ item of these policies addresses health system functions of Iran. The duty separation of the health system, financing and provision of services in the field of health with the aim of responding, realizing justice and providing good treatment services to people were investigated by considering the role of the health system, including executive policymaking, strategic planning, evaluation and supervision of the Ministry of Health and Medical Education. Such affairs were done through the insurance system based on the Ministry of Health and Medical Education and the cooperation of other centers and institutions, provision of services by service providers in private and public sectors, and the coordination and organization of them according to the mechanism determined by the law. Lack of a onedimensional oversight at functions individually, regardless of the coordination and communication between functions is important. A comprehensive oversight at health system functions together in order to achieve a broad understanding of the health system in the country is necessary, since the proper performance of a function, without considering the impact of other functions, and the proportionality and coordination between functions, does not establish the successful performance of the health system as a single unit. It seems that in order to implement these policies and in the course of reforms that have been carried out more or less in recent years in the country, it is necessary to redesign interactive aspects and document them by playing a more serious role of the government in the coordination of organizations and relevant institutions and legal requirements in order to achieve effective and healthy society.

Among the limitations of the present study, there was a lack of data and insufficient information in some items are notable.

\section{Conclusion}

Based on the most important findings of the research, there is a specific structure and mechanism for the implementation and optimal use of the interactive capacity of the Ministry of Health in Iran as a stewardship of health system and social insurance funds, and requires the establishment of these mechanisms in a scientific way. Utilizing the concept of interaction in the field of financing requires careful examination of conditions of each country and it is necessary to create the needed infrastructure to achieve the desired situation. The necessity of identifying interactions map in different countries is inevitable. Due to the importance of this issue, using these methods is not recommended without clear rules and structures. In this regard, it is suggested to design the appropriate administrative structure based on these methods in the Supreme Council of Insurance. The existence of a common unit at the planning level of the Ministry of Health and Social health insurances and common expert actions can be effective in interacting responses.

\section{Acknowledgments}

This manuscript is part of a $\mathrm{PhD}$ thesis defended in the College of Medical Science and Technology, Science and Research Branch, Islamic Azad University and also supported by Social Security Research Institute by contract number 20961122 in 2018.

\section{Conflict of Interests}

The authors declare that they have no competing interests.

\section{References}

1. Vashishtha VM. World health report 2008: time to go back to the basics! Indian Pediatr. 2009 Jan;46(1):49-50.

2. Schramm B. Social Health Insurance: A Contribution to the International Development Policy Debate on Universal Systems of Social Protection: Discussion Paper: Deutsche Gesellschaft Für Technische Zusammenarbeit (GTZ); 2005. 
3. Aboutorabi A, Ghiasipour M, Rezapour A, Pourreza A, Sarabi Asiabar A, Tanoomand A. Factors affecting the informal payments in public and teaching hospitals. Med J Islam Repub Iran. 2016;30:315.

4. Rezapour A, Ebadifard Azar F, Azami Aghdash S, Tanoomand A, Hosseini Shokouh SM, Yousefzadeh N, et al. Measuring equity in household's health care payments (Tehran-Iran 2013): technical points for health policy decision makers. Med J Islam Repub Iran. 2015;29:246.

5. Sarabi Asiabar A, Saleh Ardestani A, Ebadifard Azar F, Abtahi S A. The relationship between hospital managers' leadership style and effectiveness with passing managerial training courses. Med J Islam Repub Iran. 2016; 30 (1): 1219-1224.

6. Gorji HA, Mousavi S, Shojaei A, Keshavarzi A, Zare H. The challenges of strategic purchasing of healthcare services in Iran Health Insurance Organization: a qualitative study. Electronic Physician. 2018 Feb;10(2):6299-306.

7. Jooma R, Jalal S. Designing the first ever health insurance for the poor in Pakistan--a pilot project. J Pakistan Med Assoc. 2012 Jan;62(1):56-8.

8. Ogawa S, Hasegawa T, Carrin G, Kawabata K. Scaling up community health insurance: Japan's experience with the 19th century Jyorei scheme. Health Policy Plan. 2003 Sep;18(3):270-8.

9. Atun R, Aydin S, Chakraborty S, Sumer S, Aran M, Gurol I, et al. Universal health coverage in Turkey: enhancement of equity. Lancet (London, England). 2013 Jul 6;382(9886):65-99.

10. Atun R, de Andrade LO, Almeida G, Cotlear D, Dmytraczenko T, Frenz $\mathrm{P}$, et al. Health-system reform and universal health coverage in Latin America. Lancet (London, England). 2015 Mar 28;385(9974):1230-47.

11. Purcarea VL, Coculescu BI, Coculescu EC. Improving the quality of Health Care in the Romanian public health system--a priority in the reform process. J Med Life. 2015 Apr-Jun;8(2):166-70.

12. Herrera $T$. Challenges facing the finance reform of the health system in Chile. Medwave. 2014 May 28;14(4):e5958.

13. Huang K, Provan KG. Resource Tangibility and Patterns of Interaction in a Publicly Funded Health and Human Services Network. J Pub Administ Res Theory. 2007;17(3):435-54

14. Vosoogh Moghaddam A, Damari B, Alikhani S, Salarianzedeh M, Rostamigooran N, Delavari A, et al. Health in the 5th 5-years Development Plan of Iran: Main Challenges, General Policies and Strategies. Iran J Pub Health. 2013;42(Supple1):42-9.

15. Liu J, Chen T. Sleeping money: investigating the huge surpluses of social health insurance in China. Int $\mathrm{J}$ Health Care Finance Econo. 2013 Dec;13(3-4):319-31.

16. Frenk J. Bridging the divide: global lessons from evidence-based health policy in Mexico. Lancet (London, England). 2006 Sep 9;368(9539):954-61.

17. Frenk J, Gomez-Dantes O. Ethical and Human Rights Foundations of Health Policy: Lessons from Comprehensive Reform in Mexico. Health Hum Right. 2015 Dec 10;17(2):31-7.

18. Teichler U, Arimoto A, Cummings WK. The design and methods of the comparative study. The Changing Academic Profession: Springer; 2013. p. 25-35.

19. Mohamadi E, Raeisi AR, Nuhi M. Significant Improvement Points and Offering Strategies to Improve the Quality and Quantity of Health Insurance in Iran: A Qualitative Study. Health Inform Manag. 2013 2013-06-06;10(2):1-8.

20. Smith PC, Witter S. Risk pooling in health care financing: the implications for health system performance. 2004.

21. Paris V, Devaux M, Wei L. Health systems institutional characteristics. 2010

22. Cassels A, Organization WH. A guide to sector-wide approaches for health development: concepts, issues and working arrangements. 1997.

23. Sundewall J, Sahlin-Andersson K. Translations of health sector SWAps--a comparative study of health sector development cooperation in Uganda, Zambia and Bangladesh. Health Policy (Amsterdam, Netherlands). 2006 May;76(3):277-87.

24. Peters DH. Better health systems for India's poor: findings, analysis, and options: World Bank Publications; 2002.

25. Maeda A, Araujo E, Cashin C, Harris J, Ikegami N, Reich MR. Universal health coverage for inclusive and sustainable development: a synthesis of 11 country case studies: World Bank Publications; 2014.
26. Soors W, Devadasan N, Durairaj V, Criel B. Community health insurance and universal coverage: multiple paths, many rivers to cross. 2010.

27. Barrientos A, Lloyd-Sherlock P. Reforming health insurance in Argentina and Chile. Health Policy Plan. 2000 Dec;15(4):417-23.

28. Fischer F, Miller GJ. Handbook of public policy analysis: theory, politics, and methods: CRC Press; 2006.

29. Carrin G, Organization WH. Community based health insurance schemes in developing countries: facts, problems and perspectives. 2003.

30. Yip W, Hsiao WC. The Chinese health system at a crossroads. Health Affairs. 2008;27(2):460-8.

31. Travis P, Bennett S, Haines A, Pang T, Bhutta Z, Hyder AA, et al. Overcoming health-systems constraints to achieve the Millennium Development Goals. The Lancet. 2004;364(9437):900-6.

32. Shi G, O'Rourke M, Liu J, Zhong D, Liu X, Li J. Organisational reform in healthcare in China: impacts on the social functions of public hospitals. Australian health review: a publication of the Australian Hospital Association. 2003;26(3):61-72.

33. Tinsley LJ, Hall SA, McKinlay JB. Has Massachusetts health care reform worked for the working poor? Results from an analysis of opportunity. Ann Epidemiol. 2014 Apr;24(4):312-8. 